\title{
Slaughterhouse survey of culled female camels (Camelus dromedarius) in southeast Algeria: Fetal wastage and pregnancy characteristics
}

\author{
Mohammed Hocine Benaissa ${ }^{1,2 *}$, Bernard Faye ${ }^{3}$, Curtis R. Youngs ${ }^{4}$, Rachid Kaidi ${ }^{5}$ \\ ${ }^{1}$ Scientific and Technical Research Centre for Arid Areas (CRSTRA), Biophysical Station, PB 30240, Nezla, Touggourt, Algeria, ${ }^{2}$ Higher \\ National Veterinary School, PB 161 HacèneBadi, EL Harrach, Algiers, Algeria, ${ }^{3}$ UMR SELMET, Centre de Coopération Internationale en \\ recherche agronomique pour le développement (CIRAD-ES). Montpellier, France, ${ }^{4}$ Animal Science Department, lowa State University, Ames, \\ IA 50011 U.S.A., ${ }^{5}$ Institute of Veterinary Sciences, LBRA, University of Blida 1, PB 270, Soumaa, Blida, Algeria
}

\section{A B S TR A C T}

\begin{abstract}
This study determined the prevalence of fetal wastage due to slaughter of pregnant camels, and the relationship between fetal wastage and factors such as breed, season, abattoir location, and age. Pregnancy characteristics of indigenous camels were also investigated. Reproductive tracts were collected from 912 female camels at two abattoirs in southeast Algeria over 2.5 years. Before slaughter, data regarding reasons for culling were obtained. Pregnancy was detected in $21.7 \%$ of camels and was higher $(P<0.05)$ in the Targui than Sahraoui breed. Fetal wastage was higher $(P<0.05)$ in the dry than wet season. Fetal wastage in the first and second trimester $(57.1 \%$ of total waste) was greater $(\mathrm{P}<0.05)$ than that in third and fourth trimester $(42.9 \%$ of total). Right and left ovaries showed equal ovulatory activity. Mean diameter of the corpus luteum $(C L)$ was higher $(P<0.05)$ in females with a single corpus luteum than in those with twin or triple CLs. All but one camel carried the fetus in the left uterine horn. Embryo migration was observed in $50 \%$ of pregnant camels, and migration was from the right to left uterine horn in all cases. Prevalence of embryonic and fetal loss was $10.0 \%$ and was influenced by ovulation rate. The two most prevalent reasons for culling pregnant camels were old age (23.7\%) and poor body condition (11.6\%). These findings document the magnitude of fetal wastage which represents substantial economic loss to the camel industry. Livestock owners should receive education on reproductive management, including pregnancy testing, to minimize fetal wastage.
\end{abstract}

Keywords: Pregnancy; Camels; Season; Corpus luteum; Embryo migration; Algeria

\section{INTRODUCTION}

The livestock sector plays an important role in food security of rural populations in Algeria. In the Saharan regions of the country, camels provide more than $33 \%$ of the meat consumed in southern Algeria (Adamou et al., 2009). In these arid zones, camels are a good source of animal protein at a low cost compared with other domestic red meat species (Kadim et al., 2008).

Camel meat is coarse, tough, watery, and rather sweet in taste compared with meats from other farm animals (Kadim et al., 2013). Although the quality characteristics of camel meat are not as good as those from other animals, the demand, price, and consumption of camel meat is on the increase, both in Algeria (Adamou et al., 2009) and worldwide (Faye et al., 2013).
In Algeria, most livestock production involves animal management and production systems that are based on ancestral practices (Adamou, 2008; Benaissa et al., 2012). In such traditional livestock herds, reproductive management practices are largely based on uncontrolled natural mating and unplanned cross-breeding programs. Because veterinary services in these systems are limited, pregnancy diagnosis is still traditionally based on farmer observation. Advanced techniques such as rectal palpation and ultrasonography are not used. This lack of routine pregnancy testing results in the slaughter of pregnant females and wastage of viable fetuses.

Fetal wastage in abattoirs hinders growth of the livestock population (Cadmus and Adesokan, 2010 Cadmus and Adesokan, 2010), yet this subject has received little attention in Algeria. The slaughter of productive, clinically healthy

\footnotetext{
*Corresponding author:

Mohammed Hocine Benaissa, Scientific and Technical Research Centre for Arid Areas (CRSTRA), Biophysical Station, PB 30240, Nezla, Touggourt, Algeria, Fax: +213296496 94. E-mail: ben.medhocine@gmail.com
} 
animals at different stages of pregnancy and converting them into meat has been reported in other parts of the world. This practice is becoming a very serious constraint to future livestock populations (Fayemi and Muchenje, 2013). The frequency of fetal wastage through slaughtering of pregnant animals has been reported for several animal species, including cattle (Ladds et al., 1975; Cadmus and Adesokan, 2010; Alhaji, 2011; Alawa et al., 2011), sheep (Alosta et al., 1998; Kheradmand et al., 2006; Regassa et al., 2007), goats (Alawa et al., 2011), and camels (Ataja and Uko, 1994; Abubakar et al., 2010; Bello et al., 2012).

The economic loss due to slaughtering pregnant females includes the wastage of unborn offspring as well as the loss of reproductively functional females. In some cases, the practice of slaughtering pregnant females is performed to provide immediate cash to farmers (Kheradmand et al., 2006). In other cases, foot lesions, poor body condition, diseased status, and other problems contribute to the culling of pregnant females (Knauer et al., 2007).

To our knowledge, the extent of reproductive wastage in camels and the reasons for culling breeding females in Algeria have not been determined. Additionally, there is currently no published information concerning the reproductive characteristics of Algerian native camels. The present study was performed to obtain further information on the reproductive status of slaughtered female camels; to evaluate the rate of fetal wastage; and to document reproductive aspects such as ovarian activity, embryonic transuterine migration, and embryonic and fetal loss data in female camels. Abattoirs are an important source of information regarding reproductive characteristics, and collection of abattoir data is particularly helpful for species where the reproductive function of females is difficult to examine clinically under field conditions. Finally, we investigated the relationship between fetal wastage and breed, season and age; we also analyzed the main reasons for slaughtering pregnant females with the aim of reducing the incidence of pregnant camels being slaughtered.

\section{MATERIALS AND METHODS}

This study was an observational slaughterhouse survey performed at two municipal abattoirs (El-oued and Touggourt) in southeast Algeria (approximately $600 \mathrm{~km}$ southwest of Algiers) over a period of approximately 2.5 years from February 2011 through June 2013. Data and specimens were collected on 174 days, averaging six times per month during the study. For this study, two seasons were identified: The dry season (April to September) and the wet season (October to March).
In Algeria, almost all slaughtered camels are adults purchased from the traditional farming sector. In this study it was difficult, however, to obtain the specific geographic origins and historical data for all culled animals due to the lack of individual animal identification and the animals' associated production records.

\section{Animals}

Data were collected from 912 female camels presented by farmers or butchers to the municipal abattoirs. Preslaughter data recorded included reason for culling, estimated age, and breed. Age was estimated using dental characteristics as previously described (Schwartz and Dioli, 1992). Camels were grouped into the following four categories: a) 3-5 years of age; b) 6-10 years of age; c) $11-15$ years of age; and d) $\geq 16$ years of age. Dromedary camels common in Algeria belong to two main phenotypes Targui and Sahraoui (Oulad Belkhir et al., 2013).

\section{Examination of genital tracts and ovaries}

The reproductive tracts from all female camels were removed. Excised tracts were examined visually and by palpation to assess uterine status (pregnant or nonpregnant). Reproductive tracts from non-pregnant females were used for a different study, but tracts of pregnant females were closely inspected to determine the number, viability, sex, and location of fetuses in the uterus. The number of corpus luteum (CL) on the ovaries and their location relative to the pregnant horn were recorded.

\section{Calculation of reproductive parameters}

Ovulation rate was calculated by dividing the total number of all CLs present on all ovaries of pregnant females by the number of pregnant females. The rate of embryonic and fetal loss was calculated based on the discrepancy (if any) between of the number of CL on the ovaries and the observed number of fetuses in the uterus. Mean litter size was determined as the total number of fetuses divided by the total number of pregnant females. Transuterine embryo migration was assessed by relating the location of fetus (es) in the uterine horns to the location (ipsilateral or contralateral) of the CL (Alosta et al., 1998). The approximate gestational age was estimated from fetal crown rump length measured using a standard tape measure. Fetal age was estimated according to the equation established for camels (El-Wishy et al., 1981): $\mathrm{X}=2.1(\mathrm{Y}+17)$, where $\mathrm{X}$ is the estimated age of the fetus in days and $\mathrm{Y}$ is the crown rump length in centimeters. The stage of pregnancy was then categorized as being in the first ( $<90$ days), second (91-180 days), third (180-270 days), or fourth trimester (>270 days). Gestational age was also used to estimate the date of conception. 


\section{Statistical analysis}

Data were analyzed using descriptive and quantitative statistical tools. Farmer-reported reasons for culling were analyzed using the FREQ procedure, and significance of differences in proportions was determined using the chisquare test. The effect of breed, age category, and season on the proportion of pregnant females, as well as the distribution of CL between the right and left ovaries, were also tested using chi-square analysis. Analysis of variance was performed to determine the effect of number of ovulations on CL diameter. All analyses were performed using SPSS (SPSS. IBM Corp Ver. 20.0), and a P-value of less than 0.05 was considered statistically significant.

\section{RESULTS}

\section{Fetal wastage}

A combined total of 912 female camels was slaughtered at the Touggourt and El-Oued abattoirs from February 2011 through June 2013. Examination of the reproductive organs from these animals revealed that 198 (21.7\%) were pregnant and $714(78.3 \%)$ were not. Fetal wastage rate was $21.7 \%$ overall; the proportion of pregnant animals slaughtered did not differ $(\mathrm{P}>0.05)$ between Touggourt (18.4\% wastage [47/256]) and El-Oued abattoirs (23\% wastage [151/656]; Table 1). Breed affected fetal wastage and was higher $(\mathrm{P}<0.05)$ in Targui than Sahraoui females (Table 1).

Fluctuation in the number of slaughtered pregnant camels by season was observed. A higher $(\mathrm{P}<0.05)$ percentage of pregnant females was recorded during the dry season $(24.5 \%$ [123/502]) than in the wet season (18.3\% [75/410]; Table 1).

Age affected the proportion of pregnant females. A lower $(\mathrm{P}<0.05)$ rate of pregnant camels at slaughter was reported for camels 3-5 years of age than for camel 6 years of age or older (Table 1).

The incidence of fetal wastage varied with stage of gestation. The proportion of slaughtered camels carrying fetuses in the first and second trimesters was greater $(\mathrm{P}<0.05)$ than that in the third and fourth trimesters (Table 2).

\section{Pregnancy characteristics}

In pregnant animals, paired ovaries presented with single, double, or triple CL in 177 (89.4\%), 19 (9.6\%), and $2(1.0 \%)$ females, respectively; the ovulations were unilateral in $192(97 \%)$ and bilateral in $6(3 \%)$ of females (Fig. 1). The distribution of ovulations was not different $(\mathrm{P}>0.05)$ between the left and right ovaries. Forty eight percent of
Table 1: Relationship between fetal wastage in camels and factors such as age class, season, breed, and abattoir location

\begin{tabular}{|c|c|c|c|c|c|}
\hline \multirow[b]{2}{*}{ Age class } & \multicolumn{4}{|c|}{ Pregnant camels [No. (\%)] } & \multirow{2}{*}{$\frac{\mathrm{P} \text { value }}{*}$} \\
\hline & 3-5 yrs & $6-10$ yrs & $11-15$ yrs & $>16$ yrs & \\
\hline & $12(11)^{a}$ & $40(19.3)^{b}$ & $77(24.1)^{\mathrm{b}}$ & $69(25)^{b}$ & 0.013 \\
\hline \multirow[t]{2}{*}{ Season } & Wet & & Dry & & * \\
\hline & $75(18.3)^{a}$ & & $123(24.5)^{b}$ & & 0.024 \\
\hline \multirow[t]{2}{*}{ Breed } & Sahraoui & & Targui & & * \\
\hline & $162(20.5)^{\mathrm{a}}$ & & $36(29.5)^{\mathrm{b}}$ & & 0.025 \\
\hline Abattoir & $\begin{array}{l}\text { Touggourt } \\
47(18.4)^{\mathrm{a}}\end{array}$ & & $\begin{array}{c}\text { Eloued } \\
151(23)^{\mathrm{a}}\end{array}$ & & $\begin{array}{c}\text { NS } \\
0.278\end{array}$ \\
\hline Total & & & & & $198(100)$ \\
\hline
\end{tabular}

Table 2: Distribution of slaughtered pregnant female camels by seasons and by stage of gestation

\begin{tabular}{|c|c|c|c|c|c|c|c|c|c|c|}
\hline \multirow[t]{3}{*}{ Season } & \multicolumn{10}{|c|}{$\begin{array}{l}\text { Age of fetuses in slaughtered pregnant } \\
\text { camels (months) }\end{array}$} \\
\hline & \multicolumn{2}{|c|}{$1-3$} & \multicolumn{2}{|c|}{$3-6$} & \multicolumn{2}{|c|}{$6-9$} & \multicolumn{2}{|c|}{$>9$} & \multicolumn{2}{|c|}{ Total } \\
\hline & No. & $\%$ & 0. & $\%$ & No. & $\%$ & No. & $\%$ & No. & $\%$ \\
\hline Wet & 25 & 12.6 & 15 & 7.6 & 18 & 9.1 & 17 & 8.6 & 75 & 37.9 \\
\hline Dry & 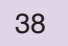 & 19.2 & 35 & 17.7 & 27 & 13.6 & 23 & 11.6 & 123 & 62. \\
\hline Total & 63 & $31.8^{x}$ & 50 & $25.3^{x}$ & 45 & $22.7^{y}$ & 40 & $20.2^{y}$ & 198 & 100 \\
\hline
\end{tabular}

a,b Means in the same column with unlike superscripts are different $(P<0.05)$,

x.yMeans in the same row with unlike superscripts are different $(P<0.05)$

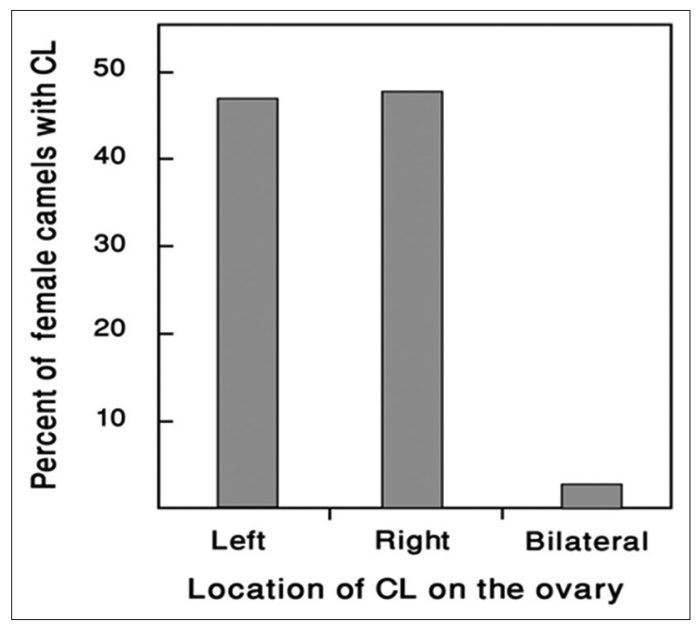

Fig 1. Distribution of corpora lutea (CL) between the right and left ovaries of 198 slaughtered female camels slaughtered during a 2.5-year period.

females had ovulations only from the left ovary, $49 \%$ of females ovulated only from the right ovary, and $3 \%$ of females ovulated from both ovaries. Mean diameter of the CL of pregnant females was $2.2 \pm 0.4 \mathrm{~cm}$ but differed $(\mathrm{P}<0.05)$ among the single, double, and triple CLs (Table 3).

All but one pregnancy was established in the left uterine horn. Fetal presentation was anterior $(\mathrm{n}=145[73.2 \%])$ more frequently $(\mathrm{P}<0.05)$ than posterior. From the total number of fetuses in which phenotypic sex could be 
Table 3: Distribution of ovulations, size of Corpora lutea, fetal wastage, and embryonic and fetal loss observed in pregnant female camels at the time of slaughter

\begin{tabular}{|c|c|c|c|c|c|c|}
\hline \multirow{2}{*}{$\begin{array}{l}\text { Location" (no.) of } \\
\text { Corpus luteum [CL] }\end{array}$} & \multirow[t]{2}{*}{ No. of females } & \multirow{2}{*}{$\begin{array}{c}\text { Diameter of CL }(\mathrm{mm}) \\
\text { mean } \pm S D(\min -\max )^{\circ}\end{array}$} & \multicolumn{3}{|c|}{ Number of fetuses } & \multirow[t]{2}{*}{ Embryonic and fetal loss (\%)* } \\
\hline & & & Observed & Expected & Lost & \\
\hline Right (1) & 87 & $2.39 \pm 0.38(1.2-3.6)$ & 87 & 87 & 0 & 0 \\
\hline Left (1) & 90 & $2.26 \pm 0.35(1.3-3.1)$ & 89 & 90 & 1 & 1.1 \\
\hline Subtotal - $1 \mathrm{CL}$ & 177 & $2.24 \pm 0.37^{a}$ & & & & $(0.6)$ \\
\hline Right (2) & 9 & $1.99 \pm 0.48(1.2-3.2)$ & 10 & 18 & 8 & 44.4 \\
\hline Left (2) & 5 & $2.23 \pm 0.54(1.5-3.7)$ & 5 & 10 & 5 & 50.0 \\
\hline Right (1) + Left (1) & 5 & $2.01 \pm 0.36(1.4-2.6)$ & 6 & 10 & 4 & 40.0 \\
\hline Subtotal - $2 \mathrm{CL}$ & 19 & $2.08 \pm 0.50^{b}$ & & & & $(44.7)$ \\
\hline Right (3) & 1 & $1.67 \pm 0.21(1.5-1.9)$ & 1 & 3 & 2 & 66.7 \\
\hline Right (1) + Left (2) & 1 & $1.77 \pm 0.36(1.5-1.9)$ & 1 & 3 & 2 & 66.7 \\
\hline Subtotal - $3 \mathrm{CL}$ & 2 & $1.72 \pm 0.20^{c}$ & & & & $(66.7)$ \\
\hline GRAND TOTAL & 198 & $2.19 \pm 0.40(1.2-3.7)$ & 199 & 221 & 22 & 10.0 \\
\hline
\end{tabular}

"Location refers to presence of the corpus luteum $(\mathrm{CL})$ on the right or left ovary, ${ }^{\circ}$ Min and max denotes the minimum and maximum diameter of the $\mathrm{CL}$, respectively, ${ }^{*}$ Figure in parentheses represents mean embryonic loss within each CL category, a,b,c Means within a column with unlike superscripts are different $(\mathrm{P}<0.01)$

determined, the male to female ratio in recovered fetuses was 1.32:1 (78 males and 59 females).

Embryonic transuterine migration was observed in 99 of 198 animals (50\%). The direction of the transuterine migration of the embryo was from the right uterine horn to the left uterine horn in $100 \%$ of cases. Evidence of embryonic and fetal loss was observed in 20 pregnant camels; Table 3 reports 22 lost embryos/fetuses with an overall percentage of embryonic and fetal loss of $10.0 \%$.

Estimation date of conception, determined by subtracting fetal age from the day of fetus collection, indicated that more than $75 \%$ of the successful mating occurred from October to March (Fig. 2).

\section{Reasons for culling pregnant females}

Farmers and butchers who presented female camels for slaughter were asked to state reasons for culling. Table 4 lists the major reasons for culling which included (in order of prevalence) old age, poor body condition, metabolic/ infectious diseases, accidents, lameness, reproductive failure, and poor productivity. Other common miscellaneous reasons for culling included items such as nasal discharge and aggressive behavior. In several cases, reasons for culling of the pregnant females were not provided.

\section{DISCUSSION}

In Algeria limited data are available on fetal wastage due to the slaughtering of pregnant females in all livestock species. In particular, factors limiting camel reproduction comprise a neglected area of research. The present study is the first to provide comprehensive data regarding the prevalence of pregnancy wastage and reasons for culling of pregnant female camels in the Sahara of Algeria. Our findings revealed
Table 4: Stated reasons for culling of pregnant female camels presented for slaughter at abattoirs in southeastern Algeria

\begin{tabular}{lcc} 
Reason for culling & $\begin{array}{c}\text { Number of } \\
\text { females }\end{array}$ & $\begin{array}{c}\text { Percentage of } \\
\text { culled females }\end{array}$ \\
\hline Old age & 47 & 23.7 \\
Poor body condition & 23 & 11.6 \\
Metabolic or infectious diseases & 19 & 9.6 \\
Accidents/trauma & 16 & 8.9 \\
Lameness & 13 & 6.6 \\
Reproductive failure & 7 & 3.5 \\
Poor production performance & 3 & 1.5 \\
Miscellaneous or unknown & 34 & 17.2 \\
conditions & & \\
No reason stated & 36 & 18.2 \\
Total & 198 & 100.0 \\
\hline
\end{tabular}

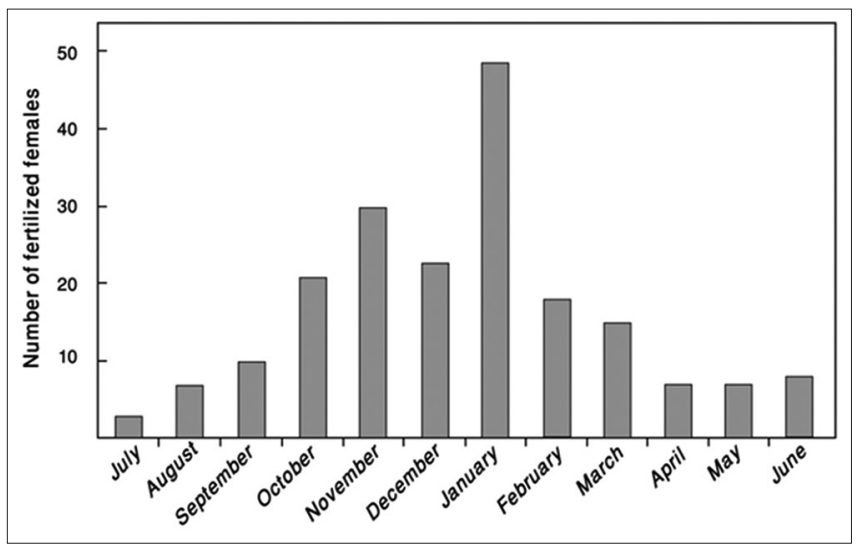

Fig 2. Distribution of the date of conception in 198 pregnant females slaughtered in southeastern Algeria during a 2.5-year period.

that more than $21 \%$ of female camels slaughtered over the survey period were pregnant. This result is consistent with fetal wastage of $\sim 24 \%$ observed in Nigeria (Ataja and Uko, 1994; Bello et al., 2012), less than $34.2 \%$ reported elsewhere in Nigeria (Abubakar et al., 2010), but more than the 14.5\% observed in Saudia Arabia (Ali, 2010). 
The practice of slaughtering pregnant females represents an economic loss to farmers as well as to the livestock industry. Female camels reach their peak productivity between the age of 10 and 15 years, yet in the present study almost half of slaughtered pregnant females were at that age. One potential explanation for this is the fact that younger male camels (which could be slaughtered for meat) generate less total income for the butcher than occurs by sale of meat from older and heavy body weight females.

** Our findings regarding fetal wastage are consistent with similar reports from other parts of the world in cattle (Ladds et al., 1975; Ndi et al., 1993; Cadmus and Adesokan, 2010; Alhaji, 2011) and in sheep (Alosta et al., 1998; Kheradmand et al., 2006; Alawa et al., 2011). These reports documented variable rates of fetal wastage ranging from $2.7 \%$ (Alawa et al., 2011) to $62.9 \%$ (Ladds et al., 1975). Slaughtering pregnant females also adversely affects meat quantity and quality (Wythes et al., 1990).

Breed of slaughtered female affected $(\mathrm{P}<0.05)$ the rate of fetal wastage. This is the first report of an effect of breed on the reproductive status of camels slaughtered for meat in Algeria. There is a lack of literature pertaining to breed differences in fetal wastage, but the difference detected in our study could be due partly to different types of farming systems and different husbandry practices. The Targui breed is taller and deeper-bodied, making it more difficult for farmers to visually see pregnancy until the female is late in gestation. Therefore, breed effects should be taken into consideration and examined in future studies.

The high percentage of pregnant females slaughtered during the dry season might be related to the increased liquidation of camels to meet the economic (cash) needs of farmers. Also, the dry season coincides with the period in which a higher proportion of females are in early pregnancy and are more likely to be misdiagnosed as non-pregnant. Our finding is consistent with those of other camel researchers (Abubakar et al., 2010; Bello et al., 2012). The distribution of fetal wastage in cattle during the dry and wet season (Ndiet al., 1993; Cadmus and Adesokan, 2010) was similar to what we observed in the camel.

Fetal wastage was influenced by age, with the lowest pregnancy rate in female camels slaughtered at 3-5 years of age. This finding is in contrast to that of Addass et al. (2010) who reported that fetal wastage of cattle, sheep, and goats is higher in the younger age groups. This difference between groups could be explained by the comparatively late age of puberty in camels compared with that for cattle, sheep and goats, as well as by the practice of slaughtering older rather than younger camels.
The pattern of fetal wastage across various stages of pregnancy observed in the present study was consistent with the findings of Wosu (1988) who reported that 42.3\%, $38.3 \%$, and $19.3 \%$ of cows slaughtered in Nigeria were in the first, second, and third trimesters of pregnancy, respectively; however, our results were contrary to the findings of Babatunde et al. (2011) who found that most of pregnant females slaughtered in Nigeria were in the last two trimesters of pregnancy. Other researchers in Cameroon (Ndi et al., 1993), Nigeria (Muhammad et al., 2007), and Australia (McLauren, 1975) also reported that second and third trimesters constituted a higher percentage of wasted fetuses. Our findings reflect remarkable fetal losses due to inability of owners to detect pregnant camels by visual inspection alone.This points to a very strong need to improve reproductive management by utilization of ultrasound or rectal palpation for pregnancy determination.

The incidence of multiple CL in the present study (10.1\%) was similar to that reported by other researchers working with dromedary camels: $12.4 \%$ (Ghoneim, 1985), 15\% (Musa and Abusineina, 1976), and 17.1\% (El-Wishy, 1988). However, Ali (2015) reported a much higher prevalence of double CLs (44.4\%). The mean diameter of CL in the present study $(2.2 \mathrm{~mm})$ was consistent with that previously reported in the literature (Zarrouk et al., 2003; Ali, 2015).

The frequency of unilateral and bilateral ovulations observed in the present study was in agreement with the report by El-Wishy (1988) in which the CLs were unilateral in $93.3 \%$ of dams. In our study, the CL distribution was equal between the left and right ovaries, similar to the report of El-Wishy (1988) and Tibary and Anouassi (1997). Other researchers reported that the CL is more often observed in the left ovary than in the right (Shalash, 1965; Ghoneim, 1985; Ali 2010). Interestingly, Yahaya et al. (1999) reported that the highest number of CLs was in the right ovary. In female camels, successful pregnancy following ovulation from the left ovary is more common (Ali 2010). Consistent with other studies (Shalash, 1965; Musa and Abusineina, 1976; El-Wishy, 1988; TibaryandAnouassi, 1997), pregnancy was located in the left uterine horn in $99.5 \%$ of cases in the present study.

Migration of embryos from the right to the left uterine horn was detected in $50 \%$ of females, similar to the findings of Musa and Abusineina (1976). Transuterine migration frequently occurs in prolific animals, although the mechanism of embryo migration may differ somewhat between species (Tsutsui et al., 2002). Hypotheses regarding the cause of embryo migration in polyovulatory species such as pigs (Dzuik et al., 1964) and dogs (Shimizu et al., 1990) who carry fetuses in both uterine horns cannot be applied to camels who typically carry a pregnancy in 
only the left uterine horn. Further studies are needed to clarify the factors associated with transuterine migration in camelids.

The male-to-female sex ratio of fetuses in the present study was consistent with the reports of Hussein et al. (1991) and Musa and Abusineina (1976), but somewhat higher than that reported by Shalash (1965), Ribadu (1988), and Bello et al. (2012) where more females than males were observed.

One of the most significant findings from our work was documentation of the relationship between the number of ovulations and embryonic and fetal loss. In monovulatory female camels, embryonic loss was extremely uncommon; contrarily, females with twin and triplet ovulations exhibited embryonic and fetal loss of $45 \%$ and $67 \%$, respectively. Although one could speculate that the failure of transuterine migration causes this loss, the high incidence of intrauterine growth retardation (IUGR) in polyovulatoryanimals occurred by the ninth week of pregnancy (Ali, 2015) suggests either lack of uterine capacity, poor placental implantation, placental crowding and/or some as of yet undocumented mechanism to reduce the number of fetuses to one similar to mares (Ginther, 1989).

Camels are seasonally breeding animals (Skidmore, 2011). The peak of the breeding season in the current study (October to March) was consistent with the observations of Sghiri et al. (1999) and Musa (2004). Our results revealed that more than $25 \%$ of matings occurred outside of (from June to October) the natural breeding season. In support of our observation, one study with well-managed camels reported that a number of females showed mating activity outside of the expected breeding season (Arthur et al., 1985).Various environmental factors such as nutrition (Tibary and Anouassi, 1997; Musa, 2004), the presence of other females (Wilson, 1984), geographical location and rainfall (Bono et al., 1989), and management system are known to modify the sexual characteristics of these seasonally breeding animals.

The overall prevalence of embryonic and fetal loss observed in this study $(10.0 \%)$ was lower than that reported by Musa and Abusineina (1976) and Ghoneim (1985). Early embryonic death syndrome in dromedaries has been reported to range from $8 \%$ to $32 \%$ (Tibary et al., 2006).

The two major reasons for culling of pregnant females were old age and poor body condition. It is highly unlikely that farmers would knowingly sell pregnant females for meat production; thus, culling decisions based solely on old age must be reconsidered as nearly one-fourth of pregnant females in the present study were slaughtered due to this reason. Poor body condition is a factor that could be potentially prevented by improved nutritional and health care management. Collectively, changes in management could greatly reduce fetal wastage and improve the economic livelihood of camel farmers.

\section{CONCLUSION}

A considerable amount of fetal wastage was detected in slaughtered camels in Algeria. The highest rate of fetal wastage occurred during the dry season and during the first and second trimesters of pregnancy, likely due to the difficulty in detecting pregnancy. Furthermore, the actual prevalence of fetal wastage in camels slaughtered throughout Algeria was most likely underestimated by this study due to uncontrolled animal slaughtering and the lack of veterinary oversight of the slaughter process. There is thus an urgent need for more effective strategies and efforts toward adequate ante-mortem inspection. Pregnancy testing in camels presented for slaughter would help to minimize fetal wastage. Slaughtering of pregnant camels is an important problem with high economic impact on livestock farmers and the country as a whole.

\section{Authors' contributions}

M.H.B (CRSTRA) was the project leader and performed most of the experiments. B.F (CIRAD France) and K.R (University of Blida) were responsible for experimental and project design. M.H.B (CRSTRA) and C.R.Y. wrote the manuscript.

\section{REFERENCES}

Abubakar, U. B., F. U. Mohammed, S. A. Shehu and I. R. A. Mustapha. 2010. Fetal wastage in camels slaughtered (Camelus dromedarius) at Maiduguri Abattoir, Borno State, Nigeria. Int. J. Trop. Med. 5: 86-88.

Adamou, A. 2008. L'élevage camelin en Algérie quel type pour quel avenir. Sécheresse. 19: 253-260.

Adamou, A., B. Bouzgueg and B. Babalhadj. 2009. Comparaison entre le rendement en carcasse chez deux populations camelines Algériennes, le Targui et le Sahraoui. Algerian J. Arid Areas. 8: 27-31.

Addass, P. A., A. O. Midau, M. Milka and M. A. Tizhe. 2010. Assessment of abattoir fetal wastage of cattle, sheep and goat in Mubi main abattoir Adamawa State, Nigeria. World J. Agric. Sci. 6: 132-137.

Alawa, C. B. I., I. Etukudo-Joseph and J. N. Alawa. 2011. A 6-year survey of pathological conditions of slaughtered animals at Zango abattoir in Zaria, Kaduna State, Nigeria. Trop. Anim. Health Prod. 43: 127-131.

Alhaji, N. B. 2011. Prevalence and economic implications of calf foetal wastage in an abattoir in Northcentral Nigeria. Trop. Anim. Health Prod. 43: 587-590. 
Ali, A. M. H. 2010. Observations on the topography of the reproductive tract of the Arabian female camel. J Agric. Vet. Sci. Qassim Univ. 3: 33-41.

Ali, A. 2015. Multiple Corpora lutea in dromedary camels: Are they associated with multiple pregnancies? Anat. Histol. Embryol. DOI: 10.1111/ahe.12223.

Alosta, R. A., L. Vaugnan and J. D. Collins. 1998. An abattoir survey of ovine reproductive tracts in Ireland. Theriogenology. 50: 457-464.

Arthur, G. H., A. T. A. Rahim and A. S. Al Hindi. 1985. Reproduction and Genital Diseases of the Camel. Bailliere and Tindall, London, Pp. 110-120.

Ataja, A. M. and B. T. Uko. 1994. Slaughter of the single humped camel (Camelus dromedarius) for meat at the Sokoto abattoir, Nigeria. Nig. J. Anim. Prod. 21: 181-185.

Babatunde, B. A. T., O. F. Adeleke, O. O. Ademola and A. A. Adesina. 2011. Frequency of slaughtering gravid cows and its economic implications in some selected parts of Ogun State, Nigeria. J. Food Agric. Environ. 9: 538-541.

Bello, A., M. A. Umaru, B. Saidu, S. Garba, M. Jibir, A. Mahmuda, S. A. Hena, A. A. Raji, Y. S. Baraya and A. A. Abubakar. 2012. Camel fetal wastage in Sokoto. Sci. J. Anim. Sci. 1: 166-170.

Benaissa, M. H., R. Mayouf, B. Hamad, M. Saidi, A. Mehdaoui and M. Belhamra. 2012. Husbandry practices of camel herders in the region of El-Oued (Southeast of Algeria). In: Proceeding of the $3^{\text {rd }}$ Conference of the ISOCARD. (Challenges Facing the Camelids in a Changing World and Climate). Pp. 163-164.

Bono, G., A. M. Dahir, A. Comin and M. A. Jumale. 1989. Plasma $\mathrm{LH}$, corticoid and sex steroid variations in camels (Camelus dromedarius) in relation to seasonal climatic changes. Anim. Reprod. Sci. 21: 101-113.

Cadmus, S. I. and H. K. Adesokan. 2010. Bovine fetal wastage in Southwestern Nigeria, a survey of some abattoirs. Trop. Anim. Health Prod. 42: 617-621.

Dzuik, P. J., C. P Polge and L. E. A Rowson. 1964. Intra-uterine migration and mixing of embryos in swine following egg transfer. J. Anim. Sci. 23: 37-42.

El-Wishy, A. B., N. A. Hemeida, M. A. Omar, A. M. Mobarak and M. A. I. El Sayed. 1981. Functional changes in the pregnant camel with special reference to fetal growth. Br. Vet. J. 137: 527-537.

El-Wishy, A. B. 1988. A study of the genital organs of the female dromedary (Camelus dromedarius). J. Reprod. Infertil. 82: 587-593.

Faye, B., O. Abdelhadi, G. Raiymbek, I. Kadim and J. F. Hocquette. 2013. La production de viande de chameau, Etat des connaissances, situation actuelle et perspectives. INRA Prod. Anim. 26: 247-258.

Fayemi, P. O. and V. Muchenje. 2013. Maternal slaughter at abattoirs: History, causes, cases and the meat industry. Springer Plus. 2: 2-7.

Ghoneim, I. M. 1985. The ovary of the pregnant camel (Camelus dromedarius) with special reference to the corpus luteum. M. $\checkmark$ Sc. Thesis, Cairo University.

Ginther, O. J. 1989. The nature of embryo reduction in mares with twin conceptuses: Deprivation hypothesis. Am. J. Vet. Res. 50: 45-53.

Hussein, E. M., N. M. Bahgat, I. E. El-Rawab and D. L. Paccamonti. 1991. Prenatal assessment of weight and dimensions of the camel conceptus (Camelus dromedarius). Anim. Reprod. Sci. 26: 129-136.

Kadim, I. T., O. Mahgoub and B. Faye. 2013. Camel Meat and Meat Products. CABI, Oxfordshire, UK.
Kadim, I. T., O. Mahgoub and R. W. Purchas. 2008. A review of the growth, and of the carcass and meat quality characteristics of the one-humped camel (Camelus dromedarius). Meat Sci. 80: 555-569.

Kheradmand, A., R. A. Batavani and H. Babaei. 2006. Study on the frequency of pregnant ewes slaughtered in Khorram Abad abattoir, Iran. Iran. J. Vet. Res. 7: 55-58.

Knauer, M., K. J. Stalder, L. Karriker, T. J. Baas, C. Johnson, T. Serenius, L. Layman and J. D. McKean. 2007. A descriptive survey of lesions from cull sows harvested at two Midwestern U.S. facilities. Prev. Vet. Med. 82: 198-212.

Ladds, P. W., P. M. Summers and J. D. Humphrey. 1975. Pregnancy in slaughtered cows in North-Eastern Australia, incidence and relationship to pregnancy diagnosis, season, age and carcass weight. Aust. Vet. J. 51: 472-477.

Mclauren, B. C. 1975. Pregnancy in slaughtered cows in NorthEastern Australia. Incidence and relationship to pregnancy diagnosis, season, age and carcass. Aust. Vet. J. 51: 472-477.

Muhammad, I. R., R. Ashiru and A. Y. Abdullahi., 2007. Implications of the slaughter of pregnant ewes and does to future stock in the semi arid urban abattoir. J. Anim. Vet. Adv. 6: 819-822.

Musa, B. E. 2004. Female Reproductive System Al-Ani F.K. Camel Management and Diseases. Al-Sharq Printing Press, Jordan.

Musa, B. E. and M. E. Abusineina. 1976. Some observations on reproduction in the female camel (C. dromedarius). Acta Vet. Beograd. 26: 63-67.

Ndi, C., N. E. Tambi and N. W. Agharih. 1993. Reducing calf wastage from slaughtering of pregnant cows in Cameroon. World Animal Review. 77: 38- 43.

Oulad Belkhir, A., A. Chehma and B. Faye. 2013. Phenotypic variability of two principal Algerian camel's populations (Targui and Sahraoui). Emirates J. Food Agric. 25: 231-237.

Regassa, F., H. Tamrat and M. Bekana. 2007. Ovarian activity, transuterine embryo migration and prenatal losses in Ethiopian highland ewes. Trop. Anim. Health. Prod. 39: 131-139.

Ribadu, A. Y. 1988. Morphological, histological and pathologic studies of genitalia of a one-humped female camel (Camelus dromedarius) in Northern Nigeria. PhD Thesis ABU Zaria, Nigeria.

Schwartz, H. J. and M. Dioli. 1992. The One - Humped Camel in Eastern Africa. A Pictorial Guide to Diseases, Health Care and Management. Verlag, Weikersheim, (Germany).

Sghiri, A. and M. A. Driancourt. 1999. Seasonal effects on fertility and ovarian follicular growth and maturation in camels (Camelus dromedarius). Anim. Reprod. Sci. 55: 223-237.

Shalash, M. R. 1965. Some reproductive aspects in the female camel. World review. Anim. Prod. 4: 103-108.

Shimizu, T., T. Tsutsui, I. Murao and H. Orima. 1990. Incidence for transuterine migration of embryos in the dog. Jap. J. Vet. Sci. 52: 1273-1275.

Skidmore, J. A. 2011. Reproductive physiology in female Old World Camelids. Anim. Reprod. Sci. 124: 148-154.

Tibary, A. and A. Anouassi. 1997. Theriogenology in Camelidae: Anatomy, Physiology, Pathology and Artificial Breeding. Veterinary Research Centre, Abu Dhabi, (United Arab Emirates), p. 489.

Tibary, A., C. Fite, A. Anouassi and A. Sghiri. 2006. Infectious causes of reproductive loss in camelids. Theriogenology. 66: 633-647.

Tsutsui, T., T. Shimizu, T. Hori and E. Kawakami. 2002. Factors affecting transuterine migration of canine embryos. J. Vet. Med. Sci. 64: 1117-1121. 
Wilson, R. T. 1984. The Camel. Longman, London, New York, Pp. 83-102.

Wosu, L. D. 1988. Calf wastage through slaughtering of pregnant cows in Enugu abattoir, Nigeria. Rev. Elev. Med. Vet. Pays Trop. 41: 97-98.

Wythes, J. R., W. R. Shorthose, G. Fordyce and D. W Underwood. 1990. Pregnancy effects on carcass and meat quality attributes of cows. Anim. Prod. 51: 461-468.
Yahaya, M. S., J. Takaashi, S. Matsuoka and O. Alakul. 1999 Ovarian activity of dromedary (single humped) camel (Camelus dromedarius) in North-Eastern Nigeria. Asian Aust. J. Anim. Sci. 12: 868-870.

Zarrouk, A., O. Souilem and J. F. Beckers. 2003. Actualités sur la reproduction chez la femelle dromadaire (Camelus dromedarius). Rev. Elev. Med. Vet. Pays Trop. 56: 95-102. 